\title{
Managing the Cloud: Establishing Standards for Describing Core Tasks of Cloud Creators, Providers, and Consumers
}

\author{
Umang Rastogi
}

\begin{abstract}
Cloud computing is an Internet-based computing technology that can be used to share resources like software, infrastructures, storage and information are delivered to consumers on their request. It also called a computing platform to share resources that comprise platform, software, applications, and business processes. So as to configuration, manufacture, and give cloud based arrangements that best address clients' issues, it is fundamental to comprehend the abilities, objectives, essential assignments, and responsibilities of the individuals or associations required all through the cloud service lifecycle. The three center jobs of Cloud Service Creator, Cloud Service Provider, and Cloud Service Consumer make the base for reflecting the nearby connection among developers, providers, and consumers so as to accomplish the ideal service flow.
\end{abstract}

Keywords: Cloud service provider, Cloud service creator.

\section{INTRODUCTION}

Cloud computing is an IT model or figuring condition made out of IT segments (equipment, programming, systems administration, and administrations) just as the procedures around the sending of these components that together empower us to create and convey cloud administrations by means of the Internet or a private system. The generating and cancellation of virtual machines running on physical equipment and being constrained by hypervisors is a cost-proficient and adaptable figuring worldview. .

Cloud computing framework and situations are less difficult that even organizations can get to the best-of-breed business applications by basically taking advantage of the cloud. It is likewise conceivable to share and advance their foundation assets at exceptionally low expenses. Despite the fact that it portrays the straightforwardness of cloud computing innovation, it really questions the security of the cloud condition.

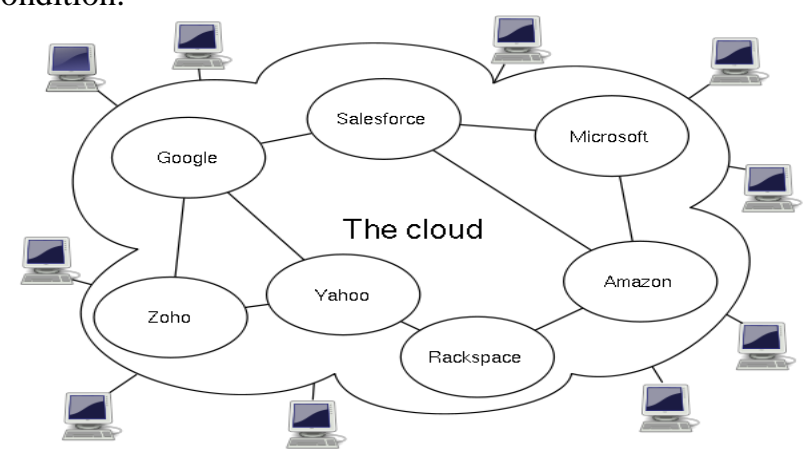

Fig.1. Cloud computing network

\section{HISTORY}

This term is obtains by communication. In 1990s, data circuits were hard-wired between ends. Hence, whole deal phone organizations started offering Virtual Private Network (VPN) administration for information correspondences. Phone organizations had the option to offer VPN-based administrations with the equivalent ensured transmission capacity as static circuits at a minor cost, accordingly using their general system data transfer capacity all the more viably. Because of this game plan, it was difficult to decide ahead of time definitely which ways the traffic would be steered over. The expression "telecom cloud" was utilized to portray this kind of systems administration, and cloud computing is theoretically to some degree comparable.

The hidden idea of cloud computing goes back to 1960, when John McCarthy opined that " computation may some time or another be sorted out as an open utility"; in reality it imparts attributes to support departments that go back to the 1960s. In 1997, the primary scholarly definition was given by Ramnath $\mathrm{K}$. Chellappa who considered it a processing worldview where the limits of registering will be controlled by financial method of reasoning instead of specialized points of confinement. The expression "cloud computing" started to show up more broadly, albeit a large portion of the concentration around then was restricted to SaaS.

Mid 2000s, Microsoft broadened the idea of SaaSby advancement of web services. IBM itemized ideas in 2001, which portrayed propelled mechanization methods, for example, self-observing, self-mending, self-arranging, and self-advancing in the administration of complex IT frameworks by way ofdissimilar capacity, servers, systems, security components, and other framework components that can be virtualized over a venture.

Amazon assumed a important job for advancement of cloud computing viarevolutionizing server farms Having discovered that the innovative cloud design brought about noteworthy interior productivity enhancements whereby, little, quick moving "two-pizza groups" could include new includes quicker and simpler, Amazon began giving access to their frameworks through Amazon Web Services on an function processing premise in 2005.

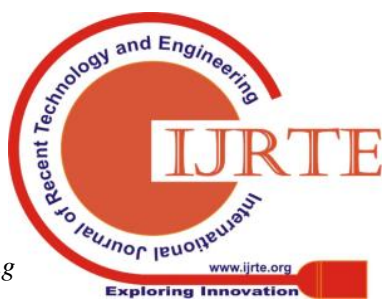




\section{ARCHITECTURE OF CLOUD COMPUTING}

The frameworks plan of the product frameworks engaged with the conveyance of cloud computing, contains $\mathrm{h} / \mathrm{w}$ and s/wplanned through a designer that regularly works for a cloud integrator. It commonly includes numerous cloud parts interconnectingwith one another above application program design interfaces, as a rule.

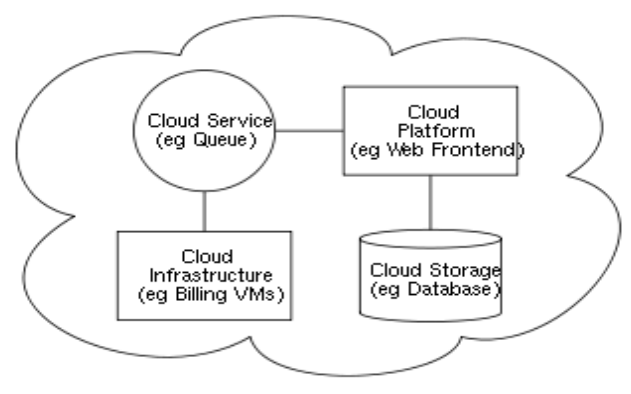

Fig.3 Cloud Computing Architecture

This intently takes after the UNIX theory of consuming various projects allundertaking one thing great and cooperating over general interfaces. Multifaceted nature is organized and the subsequent frameworks are further reasonable than their monolithic counterparts. This design reaches out to the customer, where internet browsers and additionally programming applications access cloud applications.

\section{WORKING OF CLOUD COMPUTING}

A cloud client needs a customer device, for example, a workstation or PC or any computing resources with an internet browser to get to a cloud framework by means of the WWW. Regularly the client will sign into the cloud at a specialist organization or privately owned business, for example, their manager. It takes a shot at a customer server premise utilizing internet browser conventions. The cloud gives server-based applications and all data services to the client, with yield showed on the customer device.

In the event that the client wishes to make a record utilizing a word processor, for instance, the cloud gives a reasonable application running on the server which showcases work done by the client on the customer internet browser show. Memory designated to the customer framework's internet browser is utilized to cause the application information to show up on the customer framework show, however all computations and changes are recorded by the server, and conclusive outcomes including documents made or adjusted are for all time put away on the cloud servers.

Cloud services effort on at numerous stages, including Linux, Macintosh, and Windows PCs. Advanced cells, cushions and tablet devices with Internet and WWW get to likewise give cloud services to working from home and versatile clients. A specialist co-op may pool the preparing intensity of various remote $\mathrm{PCs}$ in a cloud to accomplish routine assignments, for example, backing up of a lot of information, word processing, or computationally serious work. These errands may ordinarily be troublesome, tedious, or costly for an individual client or a little organization to achieve, particularly with restricted processing resources and funds.

With cloud computing, customers require just a straightforward PC, for example, net books, planned in view of distributed computing, or even a Smartphone, with an association with the Internet, or an organization arrange, so as to make solicitations to and get information from the cloud, subsequently the expression "software as a service " (SaaS). Computation and storage is separated among the remote PCs so as to deal with huge volumes of both, accordingly the customer need not buy costly hardware or software to deal with the undertaking. The result of the preparing undertaking is come back to the customer over the system, subject to the speed of the Internet onnection.

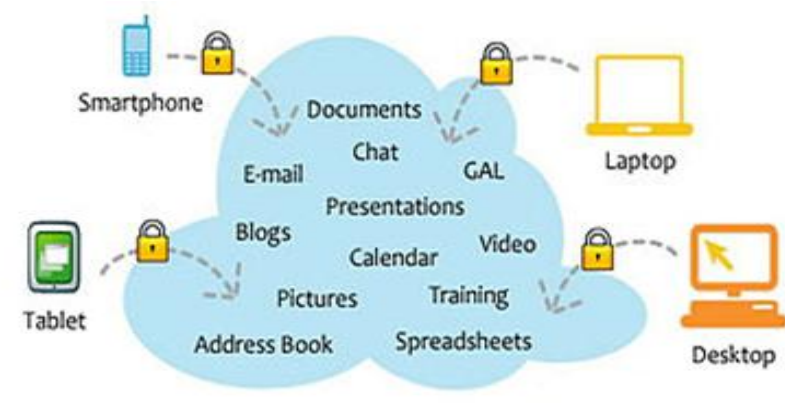

Fig 4 Cloud computing working

\section{LOUD USER ROLES}

There are some cloud user role describe in below:

- Cloud Service Provider(CSP) gives the suitable h/w and $\mathrm{s} / \mathrm{w}$ framework to execute the services and each individuals to oversee and look after the foundation.

- Cloud Service Creator (CSC) makes the person h/w and s/wmodules required for the services.

- Cloud Service Consumer acquires the services by the CSP and perhaps the CSC.

Every job may be complete by an individual or a whole association. For instance, a secretary at a specialist's workplace (the shopper) can utilize a specific, many-occupant application for overseeing tolerant protection rights, that's facilitated on the web (by the supplier) and was made by a outsider seller (the maker).

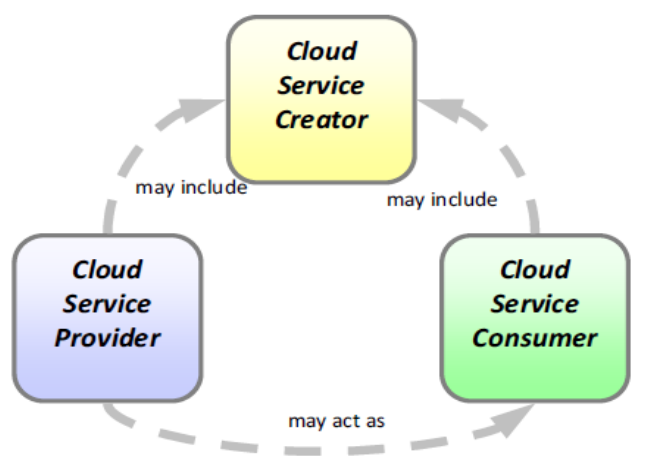

Fig 5: Cloud user role 


\section{ADVANTAGES OF USING CLOUD}

The favorable circumstances for utilizing cloud services can be of specialized, building, business and so on.

\section{Cloud Providers' perspective}

(a) Most of the server farms today are under used. They are for the most part $15 \%$ used. These server farms need save limit just to adapt to the enormous spikes that occasionally get in the server utilization. Enormous organizations having those server farms can without much of a stretch lease those computing capacity to other associations and receive benefit in return and furthermore make the resources required for running server farm used appropriately.

(b) Companies having enormous server farms have just conveyed the resources and to give cloud services they would require next to no venture and the expense would be gradual.

\section{Cloud Users' perspective}

(a) Cloud customershas no need toattentionfor $\mathrm{h} / \mathrm{w}$ and $\mathrm{s} / \mathrm{w}$ they usage and furthermore they do not need to be stressed over upkeep. Clients are never again attached to somebody conventional framework.

(b) Virtualization methodology provides the dream to clients which are taking every one of the resources accessible.

(c) Cloud clients can utilize the resources on interest premise. So the clients can strategyfine for diminishing the use to limit consumption.

(d) Scalability is one of the significant favorable circumstances to cloud clients. Adaptability is given powerfully to the clients. Clients get as much assets as they need. In this manner this model flawlessly fits in the administration of uncommon spikes in the interest.

\section{RESULT AND CONCLUSION}

We built up a system for the meaning of a single cloud client job just as the scientific categorization of the aggregate of cloud jobs. Growing from the three center cloud role presented above, we stretched out the arrangement of jobs to nearly 30 increasingly point by point maker, provider and consumer roles. As cloud computing implementation becomes over the coming years, the actions and duties of individuals who construct and support frameworks inside their organizations will change. The connections among colleagues and affiliates will be key influencers on the advancement of the cloud job definitions.

\section{REFERENCES}

[1] Ohlman, B., Eriksson, A., Rembarz, R. (2009) WhatNetworking of Information Can Do for Cloud Computing.The 18th IEEE International Workshops on Enabling Technologies: Infrastructures for Collaborative Enterprises,Groningen, The Netherlands, June 29 - July 1, 2009.

[2] K. Vijesh, P. Santhadevi "Cloud Computing: A BeginnersPrimer", International Journal for Research in Applied Scienceand Engineering Technology (IJRASET), Volume 2 Issue VII,July 2014, Page No: $42-52$

[3] SonamSudha, Ms.VasudhaArora "Identity and AccessManagement in Cloud Computing", International Journal forResearch in Applied
Science and Engineering Technology(IJRASET), Volume 2 Issue VII, July 2014, Page No: 146-153

[4] Anil Behal, Dr. Harish Rohil "Data Encryption UsingCloud Computing", International Journal for Research inApplied Science and Engineering Technology (IJRASET),Volume 2 Issue VII, July 2014 Page No: 234-241

[5] SatveerKaur and Amanpreet Singh "The concept ou Cloud Computingand Issues regarding its Privacy and Security" International Journal of Engineering Research \& Technology (IJERT), Vol 1 Issue 3, May2012.

[6] FarzadSabahi "Cloud Computing Security threats and Responses",2011 IEEE 3rd International Conuerence on Communication Soutwareand Network (ICCSN), pp. 245-249, May 2011.

[7] V. Krishna Reddy, B. ThirumalRao, Dr. L.S.S. Reddy, P.SaiKiran"Research Issues in Cloud Computing " Global Journal ou ComputerScience and Technology, Volume 11, Issue 11, July 2011.

[8] Agarwal, A. and Agarwal, A. (2011). The Security Risks Associatedwith Cloud Computing. International Journal ou ComputerApplications in Engineering Sciences, 1 (Special Issue on CNS), 257-259.

[9] Hashizume et al. (2013). An analysis ou security issues uor cloudcomputing. Journal ou Internet Services and Applications, 4(5), $1-13$.

[10] Marston, S., Li, Z., Bandyopadhyay, S., Zhang, J., Ghalsasi, A.: Cloud computing - The Business Perspective. Decis. Support Syst. 51, 176-189 (2011) 